\title{
Tumor Lysis Syndrome after the Administration of Ruxolitinib in a Patient with Post-polycythemia Vera Myelofibrosis
}

\author{
Megumi Koshiishi, Yuki Sueki, Ichiro Kawashima, Kei Nakajima, \\ Toru Mitsumori and Keita Kirito
}

\begin{abstract}
:
The development of tumor lysis syndrome (TLS) in association with treatment for myeloproliferative neoplasms (MPNs) is relatively rare. We herein present the case of a post-polycythemia vera (PV) myelofibrosis patient with massive splenomegaly who developed laboratory TLS after treatment with ruxolitinib, a potent JAK1/JAK2 inhibitor. She also exhibited a rapid reduction of spleen volume. Our present case suggests the potential risk of TLS development after ruxolitinib treatment, particularly in patients with massive splenomegaly.
\end{abstract}

Key words: ruxolitinib, myelofibrosis, splenomegaly, tumor lysis syndrome

(Intern Med 56: 2335-2338, 2017)

(DOI: 10.2169/internalmedicine.8706-16)

\section{Introduction}

Ruxolitinib is an oral JAK1 and JAK2 kinase inhibitor. The drug was recently approved in the United States, European countries and Japan for the treatment of myelofibrosis and polycythemia vera $(\mathrm{PV})$. Two major randomized controlled studies demonstrated that ruxolitinib drastically reduced the spleen volume and improved constitutional symptoms in comparison to a placebo (1), and the best available therapy (2), in high-risk myelofibrosis patients. Ruxolitinib also effectively reduced spleen size in PV patients who were refractory to or intolerant of hydroxyurea (3). The most frequent toxicities associated with ruxolitinib are anemia and thrombocytopenia. Thus, experts emphasize the importance of careful dose modification in individual patients according to their blood cell counts (4). However, although rare, other serious adverse events have been reported in ruxolitinibtreated patients. First, ruxolitinib increases the risk for opportunistic infections, including disseminated tuberculosis, Pneumocystis jiroveci pneumonia and the reactivation of the hepatitis B virus (5). The second serious adverse event is ruxolitinib withdrawal syndrome, which is characterized by the rapid development of respiratory failure, accelerated splenomegaly and the acute relapse of disease symptoms (6). In addition to these toxicities, we herein demonstrate that tumor lysis syndrome (TLS) may develop as a potentially serious adverse event in patients who receive ruxolitinib treatment. A patient with post-PV myelofibrosis with huge splenomegaly rapidly developed TLS after the initiation of ruxolitinib treatment. To our knowledge, this is the first report of TLS associated with the administration of ruxolitinib.

\section{Case Report}

A 62-year-old woman with a 20-year history of PV developed massive splenomegaly. She had a history of cerebral infarction and hydoxyurea had been used to treat her highrisk PV for 10 years. A bone marrow biopsy revealed an increase in reticulin and collagen fibers that was classified as MF-3 grade according to the European consensus on the grading of bone marrow fibrosis (7). Based on these findings, the patient was diagnosed with post-PV myelofibrosis. She was enrolled in an AJP-01 study (8), and treatment with ruxolitinib (10 $\mathrm{mg}$, b.i.d.) was initiated according to the pro- 


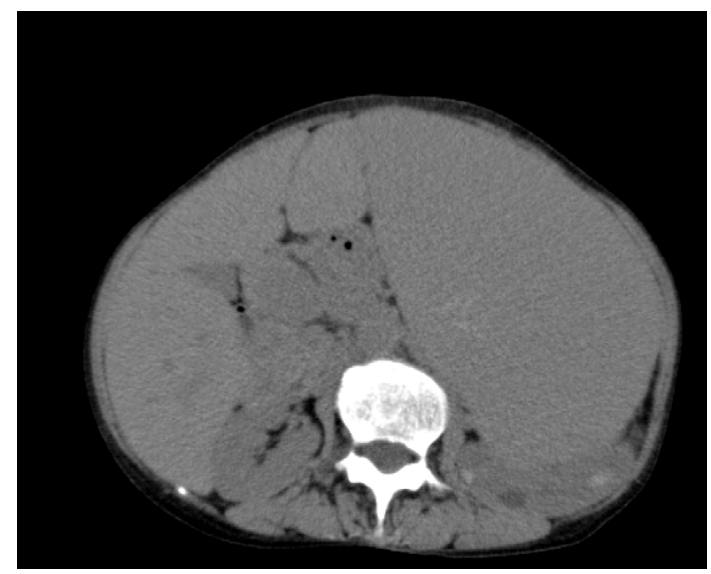

Figure 1. CT images from before the initiation of ruxolitinib treatment. The CT scan revealed massive splenomegaly.

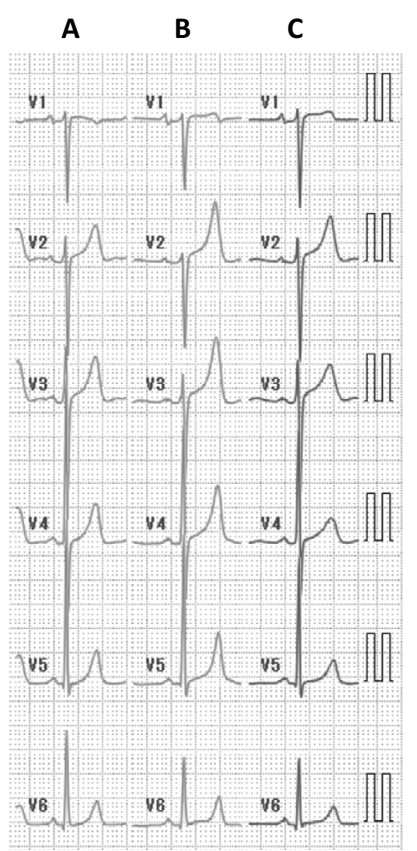

Figure 2. Changes in the electrocardiogram. (A) Before starting ruxolitinib. (B) Seven days after the initiation of ruxolitinib treatment. (C) After treatment for tumor lysis syndrome.

tocol. She had significant splenomegaly at that the time of enrollment. The lower end of the spleen was $39 \mathrm{~cm}$ from the costal margin (Fig. 1). On the initiation of ruxolitinib treatment, hematogram exhibited a white blood cell count of $24.0 \times 10^{9} / \mathrm{L}$ (reference range, $3.67-9.65 \times 10^{9} / \mathrm{L}$ ), a hemoglobin level of $11.2 \mathrm{~g} / \mathrm{dL}$ (reference range, 11.1-14.8 g/dL) and a platelet count of $725 \times 10^{9} / \mathrm{L}$ (reference range, $155-348 \times 10^{9} /$ L). Her biochemical values were as follows: serum creatine, $0.61 \mathrm{mg} / \mathrm{dL}$; potassium $(\mathrm{K}), 4.5 \mathrm{mmol} / \mathrm{L}$ (reference range, $3.4-4.8 \mathrm{mmol} / \mathrm{L}$ ); and uric acid, $5.6 \mathrm{mg} / \mathrm{dL}$ (reference range, 2.6-5.7 mg/dL). An electrocardiogram exhibited normal findings (Fig. 2A). Seven days after the initiation of ruxolitinib treatment, she visited our hospital for a routine examination. Although her hematogram only exhibited a modest change after the initiation of ruxolitinib (white blood cell count,
Table 1. The Laboratory Findings of the Patient at the Diagnosis of LTLS.

\begin{tabular}{crlr}
\hline \multicolumn{2}{c}{ Blood Cell count } & \multicolumn{2}{l}{ Serum Biochemistry } \\
\hline WBC & $24.1 \times 10^{9} / \mathrm{L}$ & TP & $7.6 \mathrm{~g} / \mathrm{dL}$ \\
Mbl & $1 \%$ & Alb & $4.1 \mathrm{~g} / \mathrm{dL}$ \\
Myelo & $3 \%$ & T-bil & $0.5 \mathrm{mg} / \mathrm{dL}$ \\
Meta & $8 \%$ & AST & $32 \mathrm{U} / \mathrm{L}$ \\
Stab & $3 \%$ & ALT & $24 \mathrm{U} / \mathrm{L}$ \\
Seg & $52 \%$ & LDH & $950 \mathrm{U} / \mathrm{L}$ \\
Ebl & $1 \%$ & BUN & $26.4 \mathrm{mg} / \mathrm{dL}$ \\
Eo & $4 \%$ & Cre & $0.67 \mathrm{mg} / \mathrm{dL}$ \\
Baso & $7 \%$ & UA & $5.8 \mathrm{mg} / \mathrm{dL}$ \\
Lymph & $19 \%$ & Ca & $8.6 \mathrm{mg} / \mathrm{dL}$ \\
Mono & $3 \%$ & $\mathrm{P}$ & $5.3 \mathrm{mg} / \mathrm{dL}$ \\
RBC & $5.14 \times 10^{12} / \mathrm{L}$ & $\mathrm{Na}$ & $134 \mathrm{mmol} / \mathrm{L}$ \\
Hb & $11.2 \mathrm{~g} / \mathrm{dL}$ & $\mathrm{K}$ & $7.3 \mathrm{mmol} / \mathrm{L}$ \\
Plt & $644 \times 10^{9} / \mathrm{L}$ & & \\
\hline
\end{tabular}

$24.1 \times 10^{9} / \mathrm{L}$; and platelets, $644 \times 10^{9} / \mathrm{L}$ ), the size of her spleen was markedly reduced. The lower margin of the spleen was $19 \mathrm{~cm}$ from the costal margin. However, her potassium levels were drastically increased $(7.3 \mathrm{mmol} / \mathrm{L})$, and an abnormal increase in the height of the T-waves was noted on her electrocardiogram (Fig. 2B). Her serum uric acid levels were also increased above the reference range $(7.2 \mathrm{mg} / \mathrm{dL})$. The other laboratory findings are shown in Table 1. Based on these findings, we diagnosed the patient with laboratory TLS according to the criteria proposed by Cairo et al. (9) and the TLS guidelines proposed by the Japanese Society of Medical Oncology (10). We immediately started treatment with hydration and intravenous insulin with glucose infusion. The administration of sodium polystyrene sulfonate was also initiated (Fig. 3). The dose of ruxolitinib was reduced to $10 \mathrm{mg}$ (b.i.d.). The next day, her potassium levels normalized $(4.3 \mathrm{mmol} / \mathrm{L})$, and the abnormal peak in the Twaves on her electrocardiogram also improved (Fig. 2C). Her serum uric acid levels also decreased to the normal range (Fig. 3). After the resolution of TLS, ruxolitinib treatment was continued and she showed a good spleen response.

\section{Discussion}

TLS is an oncological emergency that is characterized by metabolic abnormalities, including hyperuricemia, hypophosphatemia, hyperkalemia and hypocalcemia (11). These metabolic abnormalities typically occur spontaneously (before initiating treatment) or within several days after the initiation of anti-cancer treatment, particularly chemotherapy. The recent guidelines define two types of TLS: laboratory TLS (LTLS) and clinical TLS (CTLS). The latter state is associated with various types of clinical abnormalities, including seizure and arrhythmia (9).

It is well accepted that the risk of developing TLS differs according to the type of malignancy (9). Patients with acute lymphoblastic leukemia with excess blast cells or Burkitt 


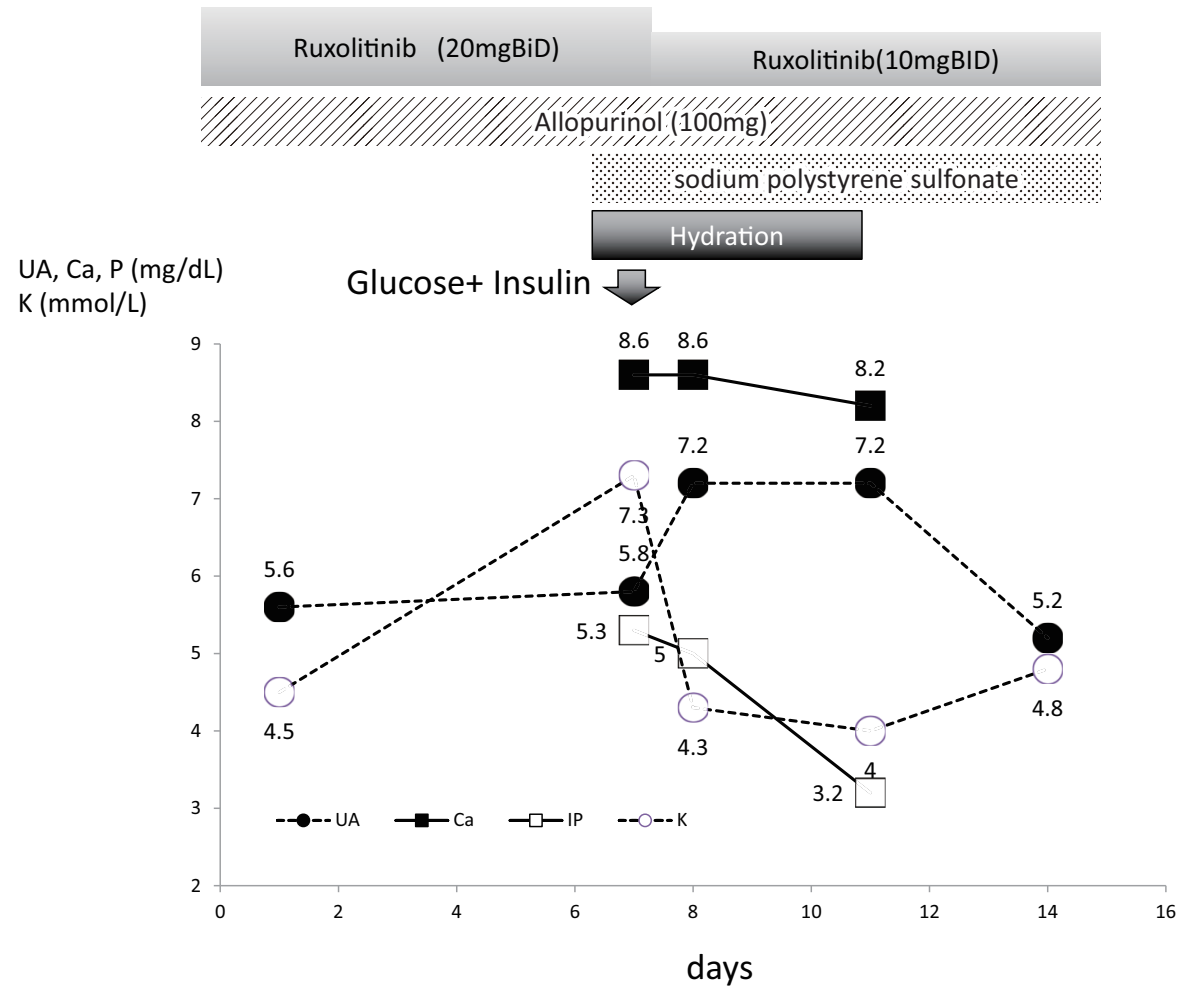

Figure 3. The clinical course of the patient. The serum uric acid (UA), potassium (K), calcium (Ca) and phosphate $(\mathbf{P})$ levels are shown.

Table 2. Summary of the Philadelphia-negative MPN Cases in which TLS Developed.

\begin{tabular}{|c|c|c|c|c|c|c|c|}
\hline Reference & Age & Sex & Diagnosis & Spleen size & Cause of TLS & Treatment for TLS & Outcome \\
\hline 12 & 63 & M & blastic phase PV & spleen enlarged & spontaneously & hydration, allopurinol & $\begin{array}{l}\text { died within } \\
2 \text { days }\end{array}$ \\
\hline 13 & 81 & M & blastic phase PV & $\begin{array}{l}\text { massive } \\
\text { splenomegaly }\end{array}$ & $\begin{array}{l}14 \text { days after } \\
\text { administration of } \mathrm{HU}\end{array}$ & hemodialysis & recovered \\
\hline 14 & 66 & $\mathrm{~F}$ & $\begin{array}{l}\text { post PV } \\
\text { myelofibrosis }\end{array}$ & $\begin{array}{l}\text { massive } \\
\text { splenomegaly }\end{array}$ & splenic irradiation & hydration, allopurinol & recovered \\
\hline 16 & 47 & M & PMF & $\begin{array}{l}\text { extreme } \\
\text { splenomegaly }\end{array}$ & $\begin{array}{l}\text { spontanesouly, } \\
\text { hydronephrosis due to } \\
\text { stones in bilateral ureteral } \\
\text { stones }\end{array}$ & $\begin{array}{l}\text { bilateral ureteral stent, hydration, } \\
\text { allopurinol }\end{array}$ & recovered \\
\hline 17 & 70 & $\mathrm{~F}$ & $\begin{array}{l}\text { post PV } \\
\text { myelofibrosis }\end{array}$ & $\begin{array}{l}\text { massive } \\
\text { splenomegaly }\end{array}$ & ruxolitinib withdrawal & $\begin{array}{l}\text { hydration, } \\
\text { sodium polystyrene sulfonate, } \\
\text { intravenous insulin and glucose, } \\
\text { rasburicase }\end{array}$ & recovered \\
\hline This case & 62 & $\mathrm{~F}$ & $\begin{array}{l}\text { post PV } \\
\text { myelofibrosis }\end{array}$ & $\begin{array}{l}\text { massibe } \\
\text { splenomegaly }\end{array}$ & ruxolitinib admisistration & $\begin{array}{l}\text { hydration, } \\
\text { sodium polystyrene sulfonate, } \\
\text { intravenous insulin and glucose, } \\
\text { allopurinol }\end{array}$ & recovered \\
\hline
\end{tabular}

PV: polycythemia vera, PMF: primary myelofibrosis, HU: Hydroxyurea

lymphoma have a very high risk of developing TLS. Conversely, the risk of developing TLS is thought to be extremely low in patients with myeloproliferative neoplasms (MPNs). To date, only a small number of cases of TLS have been reported in association with Philadelphia-negative MPNs (Table 2). Hentrich et al. reported the case of a PV patient who proceeded to acute myeloid leukemia (AML) with an extremely high number of white blood cells who spontaneously developed serious TLS (12). Ellis et al. reported the case of a PV patient in the blastic phase with TLS after treatment with hydroxyurea (13). Jain et al. reported the case of a myelofibrosis patient with TLS after splenic irradiation (14). In addition to these reports, three additional cases of myelofibrosis with TLS have been reported (15-17).

Although the disease-specific risk of TLS in MPNs might 
be very low, the introduction of molecular target therapy might increase the risk of TLS. There are several reports of patients with chronic myelogenous leukemia who developed TLS after the initiation of tyrosine kinase inhibitor treatment (18-20). The JAK inhibitor ruxolitinib has been shown to significantly improve splenomegaly both in myelofibrosis and PV patients (1-3). The decrease in the spleen size is rapid, and most cases achieved a $>35 \%$ reduction in spleen volume, within a few weeks after the initiation of ruxolitinib treatment. Consistent with these findings, a rapid and significant reduction of spleen size was observed in the present case. Although the hypothesis is currently speculative, the rapid reduction of the spleen mass by ruxolitinib may have triggered the development of TLS in our patient. Interestingly, as shown in Table 2, all of the Philadelphia-negative MPN patients who presented TLS had massive splenomegaly. Furthermore, a case report by Chen et al. suggested that splenic irradiation caused clinical TLS in a patient with chronic myelogenous leukemia, which also supports this hypothesis (21). It is well accepted that renal impairment and/or the renal involvement of tumors increases the risk of TLS (9); however, the present case showed a normal renal function as presented in Table 1.

Physicians should be aware of the potential risk of ruxolitinib treatment-associated TLS, particularly in patients who exhibit massive splenomegaly. In addition, it is important to record the cases of patients who develop TLS after ruxolitinib treatment to accurately evaluate the potential risk of TLS in patients who are treated with ruxolitinib.

\section{Author's disclosure of potential Conflicts of Interest (COI).}

Keita Kirito: Honoraria, Novartis Pharma.

\section{References}

1. Verstovsek S, Mesa RA, Gotlib J, et al. A double-blind, placebocontrolled trial of ruxolitinib for myelofibrosis. N Engl J Med 366: 799-807, 2012.

2. Harrison C, Kiladjian JJ, Al-Ali HK, et al. JAK inhibition with ruxolitinib versus best available therapy for myelofibrosis. N Engl J Med 366: 787-798, 2012.

3. Vannucchi AM, Kiladjian JJ, Griesshammer M, et al. Ruxolitinib versus standard therapy for the treatment of polycythemia vera. $\mathrm{N}$ Engl J Med 372: 426-435, 2015.

4. Mesa RA, Komrokji RS, Verstovsek S. Ruxolitinib dose management as a key to long-term treatment success. Int J Hematol 104: 420-429, 2016.

5. Heine A, Brossart P, Wolf D. Ruxolitinib is a potent immunosuppressive compound: is it time for anti-infective prophylaxis? Blood 122: 3843-3844, 2013.
6. Tefferi A, Pardanani A. Serious adverse events during ruxolitinib treatment discontinuation in patients with myelofibrosis. Mayo Clin Proc 86: 1188-1191, 2011.

7. Thiele J, Kvasnicka HM, Facchetti F, Franco V, van der Walt J, Orazi A. European consensus on grading bone marrow fibrosis and assessment of cellularity. Haematologica 90: 1128, 2005.

8. Komatsu N, Kirito K, Shimoda K, et al. Assessing the safety and efficacy of ruxolitinib in a multicenter, open-label study in Japanese patients with myelofibrosis. Int J Hematol 105: 309-317, 2017.

9. Cairo MS, Coiffier B, Reiter A, Younes A. Recommendations for the evaluation of risk and prophylaxis of tumour lysis syndrome (TLS) in adults and children with malignant diseases: an expert TLS panel consensus. Br J Haematol 149: 578-586, 2010.

10. TLS guidance. Japanese Society of Medical Oncology, Ed. Kanehara-shuppan, Tokyo, 2013.

11. Howard SC, Jones DP, Pui CH. The tumor lysis syndrome. N Engl J Med 364: 1844-1854, 2011.

12. Hentrich M, Rockstroh J, Sandner R, Brack N, Hartenstein R. Acute myelogenous leukaemia and myelomonocytic blast crisis following polycytemia vera in HIV positive patients: report of cases and review of the literature. Ann Oncol 11: 195-200, 2000.

13. Ellis AK, Lee DH. Tumor lysis syndrome induced by hydroxyurea therapy for leukemic transformation of polycythemia vera. Am J Hematol 71: 237-238, 2002.

14. Jain S, Harrison C, McMullin MF, Houston RF. Tumour lysis syndrome after splenic irradiation in a patient with JAK2 V617F postpolycythaemia vera myelofibrosis. Clin Oncol 22: 893, 2010.

15. Cvetković ZP, Cvetković BR, Čeleketić D, Milenković D, Peruničić-Peković G. Bilateral ureteral obstruction due to primary myelofibrosis caused hyperuricaemia. Acta Chirurgica Iugoslavica 57: 79-83, 2010.

16. Dai T, Friedman EW, Barta SK. Ruxolitinib withdrawal syndrome leading to tumor lysis. J Clin Oncol 31: e430-e432, 2013.

17. Sile S, Wall BM. Acute renal failure secondary to spontaneous acute tumor lysis syndrome in myelofibrosis. Am J Kidney Dis 38: e21.1-e.4, 2001.

18. Sonmez M, Ovali E, Omay SB. Tumor lysis syndrome during treatment with AMN107 (Nilotinib) in a patient with chronic myelogenous leukemia accelerated phase. J Clin Pharm Ther 33: 91-92, 2008.

19. Al-Kali A, Farooq S, Tfayli A. Tumor lysis syndrome after starting treatment with Gleevec in a patient with chronic myelogenous leukemia. J Clin Pharm Ther 34: 607-610, 2009.

20. Hua J, Iwaki Y, Inoue $M$, Hagihara $M$. Tumor lysis syndrome soon after treatment with hydroxyurea followed by nilotinib in two patients with chronic-phase chronic myelogenous leukemia. Int J Hematol 98: 243-246, 2013.

21. Chen SW, Hwang WS, Tsao CJ, Liu HS, Huang GC. Hydroxyurea and splenic irradiation-induced tumour lysis syndrome: a case report and review of the literature. J Clin Pharm Ther 30: 623-625, 2005.

The Internal Medicine is an Open Access article distributed under the Creative Commons Attribution-NonCommercial-NoDerivatives 4.0 International License. To view the details of this license, please visit (https://creativecommons.org/licenses/ by-nc-nd/4.0/).

(C) 2017 The Japanese Society of Internal Medicine Intern Med 56: 2335-2338, 2017 